\title{
Modeling of the Stress-Strain Relationship of Wood Material Beyond Its Elasticity Limit under Cyclic Compressive Loading: Comparative Study of Two Models
}

\author{
Thierry Fothe ${ }^{1 *}$, Ulrich Gael Azeufack ${ }^{1,2}$, Bienvenu Kenmeugne ${ }^{3}$, Pierre Kisito Talla ${ }^{1}$, Médard Fogue ${ }^{2}$ \\ ${ }^{1}$ Reasearch Unit of Mechanics and Physical Systems Modeling (UR2MPS), Department of Physics, University of Dschang, \\ Dschang P.O.Box 67, Cameroon \\ ${ }^{2}$ Research Unit of Engineering of Industrial Systems and Environment (URISIE), UIT-FV Bandjoun, University of Dschang, \\ Dschang P.O.Box 134, Cameroon \\ ${ }^{3}$ Laboratoire d'Engineering Civil et Mecanique (LECM), Ecole Nationale Superieure Polytechnique de Yaoundé, Yaoundé \\ P.O.Box 8390, Cameroon
}

Corresponding Author Email: thierryfothe@gmail.com

https://doi.org/10.18280/mmep.080108

Received: 2 November 2020

Accepted: 26 January 2021

\section{Keywords:}

wood, cyclic compression, envelope curves, damage, mathematical models

\begin{abstract}
In this work, we study the relative capacities of two mathematical models for the description of the stress-strain relationship of wood material subjected to damaging cyclic compressive stresses. The models studied are the Mazars-Pijeaudier Cabot model and the Fozao-Foudjet model (Fozao-Foudjet 2). The envelope curves obtained experimentally during the cyclic compression tests were approximated using the two mathematical models and the coefficient determination $\mathrm{R}^{2}$ was calculated for each of the models. It appears from the observations that the two models present a good fit to the experimental results. In addition, the Fozao-Foudjet 2 model used with the parameters and chosen such as $0.00 \leq \lambda_{0} \leq 0.015$ and $0.99 \leq \lambda_{1} \leq 1.05$, shows a better fit to the experimental results compared to the Mazar-Pijeaudier Cabot model.
\end{abstract}

\section{INTRODUCTION}

Wood is a biological material with impressive mechanical properties whose availability and ease of processing have made it the most used material for centuries. It operates at several levels in civil engineering, shipbuilding and many other fields. Its use has seen renewed interest in recent years due to the need to promote sustainable development while respecting the environment. The use of a material in the field of mechanical construction, whether in civil engineering, shipbuilding or simply carpentry, requires a prior knowledge of the mechanical characteristics of said material. These characteristics include the physicochemical properties of the material, the mechanical properties (Young's modulus, failure load, etc.) and the likely behaviors that these materials may exhibit when subjected to certain types of common stresses. The mastery of said characteristics not only guarantees better safety conditions, but also makes optimum use of the material. The study of the material in order to guarantee better safety conditions goes through the description of the various deterioration and rupture mechanisms of this material.

A material will be well known and therefore well valued if its different plasticity and damage mechanisms are well described. This problem is the subject of several studies carried out all over the world on the material wood [1-10]. The purpose of this study is to study the stress-strain relationship of some tropical species when they are stressed beyond their elasticity limits by cyclic compressive stresses.

It is shown that beyond the yield strength, a material exhibits nonlinear behavior. This nonlinearity is attributed mainly to the phenomena of plasticity and damage. These two phenomena are sufficiently well described by damage theory

\section{$[11,12]$}

Damage is the process of gradual deterioration leading to failure of the material [11], it begins with birth followed by the growth and coalescence of micro defects. The coalescence of the micro defects is the final step in the damage process and results in the appearance within the material of macroscopic cracks, thus marking the rupture of the material [12]. The first models for describing damage appeared in the 1960s when Kachanov [13] defined a mathematical variable for describing damage. Much work has therefore emerged on the modeling of damage to materials such as metals and concrete [11-16]. The modeling of the damage is generally done within the framework of the mechanics of the continuous damage developed by the authors such as Lemaitre and Chaboche [13] whose essential points are: (1) the choice of an admissible thermodynamic potential for the establishment of the constitutive laws of the observable variables (strain, and temperature) and (2) the appropriate choice of a potential of dissipation for the evolution of the internal variables (plasticity, damage). The difference between the damage models thus proposed can therefore mainly reside in the choice of the dissipation potentials and therefore in the choice of the form of evolution of the damage variable. This choice is, however, guided by experimental observations and must be made in ways that best reproduce these experimental observations [1]. There are thus many damage models in the literature which all differ from each other in the form of the law of evolution chosen for the damage $[12,14,17]$. However, the choice of a law of evolution being conditioned by experimental observation, it depends not only on the type of material studied, but also and above all on the type of stresses. The damage models are therefore developed according to the types of stress 


\section{$[1,14]$.}

One of the stress regimes responsible for material damage is the cyclic stress regime. These cyclic stresses can be low in amplitude in which case the damage is due to fatigue of the material after a high number of cycles; just as they can be of increasing amplitude and relatively high in which case damage occurs even after a low number of cycles [12]. This second type of solicitation is the subject of this study.

The modeling of the damage under cyclic load with low number of cycles was the subject of numerous works on materials such as steels and concretes. [11-17] Despite the large number of models existing for the description of the behavior cyclic of materials such as concrete and steels, there is to our knowledge very little model describing the behavior of wood material under cyclic stress at low number of cycles [18-21]. The objective of this study is to find, among two existing damage models for modeling the behavior of materials other than wood, the one capable of best describing the cyclic behavior at low number of cycles of wood.

Many damage models have been proposed within the framework of the modeling of cyclic behaviors, a large part of these models, based on the theories of plasticity and damage; although efficient remain difficult to apply to materials, this mainly due to the large number of parameters required for their use. A model widely used for its relative simplicity is that proposed by Mazars and pijaudier-cabot [22]. It was developed by the authors for the modeling of concrete damage. This model was subsequently adopted in the literature by many authors such as: Faria; Sima; Brecolleti [23-25], among many others for modeling concrete damage under cyclic stress. Recently it has been adopted in the framework of wood damage modeling by authors such as Wang [18]. The initial model as proposed by the authors is sometimes modified in order to bring improvements in the description of the damage Sima [23-28], but these modifications all the time bring an additional number of parameters and make the model more complex and therefore more difficult to use. One of the recent modifications made to the model is that carried out by FozaoFoudjet [26] for the description of behavior of bamboo under cyclic stress. The model named Fosao-Foudjet 2 thus proposed by the authors has been shown to be more suitable for modeling the stress-deformation curves of bamboo under cyclic stress. The adoption of one or the other of these models within the framework of the modeling of the cyclic behavior of wood should be done by taking into account the capacity of the model to accurately describe the behavior studied, in this case the stress-strain relation. In this study, we are therefore interested in a comparison of the two damage models in their capacity to describe the stress-strain relationship through the envelope curves of the wood material subjected to cyclical stress. In our work, we plot the envelope curves proposed by the Mazar-Pijodiercabot and Fozao-Foudjet models, which we compare to the envelope curves obtained experimentally.

It is shown that the envelope curve of the material subjected to cyclic compression can be approximated by a stress-strain curve of monotonic compression. This monotonic compression curve includes: a linear part (zone with elastic behavior) and a nonlinear part describing the nonlinear behavior. The envelope curve is therefore generally defined by a set of parameters obtained experimentally including (1) the initial modulus of elasticity, (2) the strain at the elastic limit, (3) the coordinates at the top of the stress-strain curve, as can be seen in Figure 1.

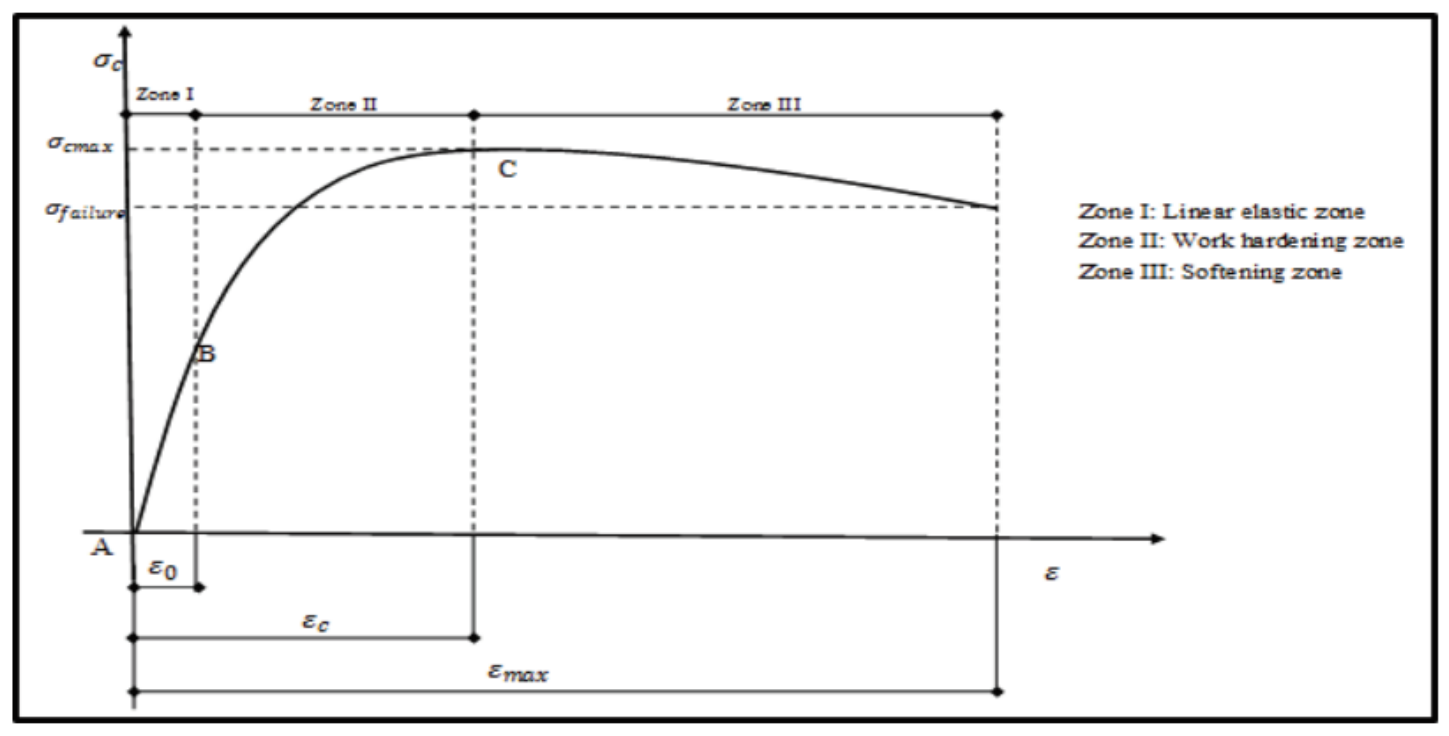

Figure 1. Typical monotonic uniaxial stress-strain curve $[23,26]$

\section{PRESENTATION OF THE STUDY MODELS AND EXPERIMENTAL METHODS}

\subsection{Presentation of models}

The models object of our study are those of Mazar-pijaudier -Cabot [22] and Fozao-Foudjet [26]. The MazarPijaudiercabot model was proposed for the description of the behavior of concrete under cyclic stress. The Fozao-Foudjet 2 model is obtained from the Mazar-pijaudiercabot model by the introduction of two parameters $\lambda_{0}$ and $\lambda_{1}$ with $1.00 \leq \lambda_{0} \leq 1.38$ and $0.0 \leq \lambda_{1} \leq 0.13$. For the description of the stress-strain relationship of bamboo. The mathematical expressions of the mazars-pijaudiercabot and Fozao-Foudjet 2 models are presented in Table 1. The original parameters were rewritten in terms of parameters obtained in the monotonic $1 \mathrm{D}$ compression tests $[23,24]$. 
Table 1. Mathematical expressions from Mazar-Pijeaudier-Cabot and from Fozao-Foudjet2 models

\begin{tabular}{|c|c|c|}
\hline & Equations of Mazar - Pijaudier cabot's models & Equation of Fozao-Foudjet's models \\
\hline 1 & $\sigma=(1-D) E_{0} \varepsilon$ & $\sigma=\left(\frac{\varepsilon_{c}}{\varepsilon_{0}}\right)^{\lambda_{1}}(1-D) E_{0} \varepsilon$ with $0.0 \leq \lambda_{1} \leq 0.13$ \\
\hline 2 & $D=1-\frac{\varepsilon_{0}}{\varepsilon}(1-B)-B \exp \left(\frac{\varepsilon_{0}-\varepsilon}{\varepsilon_{c}}\right)$ & $D=1-\frac{\varepsilon_{0}}{\varepsilon}(1-B)-B \exp \left(\frac{\varepsilon_{0}-\varepsilon}{\varepsilon_{c}}\right)$ \\
\hline 3 & $B=\frac{\left[\sigma_{c \max }-E_{0} \varepsilon_{0}\right]}{E_{0}\left[\varepsilon_{c} \exp \left(\frac{\varepsilon_{0}-\varepsilon_{c}}{\varepsilon_{c}}\right)-\varepsilon_{0}\right]}$ & $B=\frac{\left[\sigma_{c \max }-E_{0} \varepsilon_{0}\right]}{E_{0} \varepsilon_{0}\left[\left(k_{0}\right)^{\lambda_{0}} \exp \left(\frac{\varepsilon_{0}-\varepsilon_{c}}{\varepsilon_{c}}\right)-1\right]}$ \\
& & With $k_{0}=\frac{\varepsilon_{c}}{\varepsilon_{0}}$ and $1.00 \leq \lambda_{0} \leq 1.38$ \\
\hline
\end{tabular}

In these formulas,

- $\quad \sigma$ is the applied stress;

- $\sigma_{c \max }$ is the maximum applied stress;

- $E_{0}$ is the modulus of elasticity;

- $\quad D$ is the Damage of the material;

- $\varepsilon$ is the total strain;

- $\varepsilon_{0}$ is the elastic strain;

- $\varepsilon_{c}$ is the strain at the maximum applied stress;

- $\quad \lambda_{0}$ and $\lambda_{1}$ are parameters of Fozao-Foudjet 2 model.

The parameters $E_{0}, \varepsilon_{0}, \varepsilon_{c} \sigma_{c \max }$ are obtained by the of a monotonic compression curve. This relatively small number of parameters makes the simplicity of the model and can explain its recurring choice in the modeling of cyclic behaviors. In Revenge the parameters $\lambda_{0}$ and $\lambda_{1}$ are obtained by digital calibration.

\subsection{Experimental set-up for cyclic compression tests.}

The experimental results used in this study are those obtained by Fothe et al. [29] when studying the damage of wood subjected to cyclic compressive loads. Thus, the details of the experimental tests will not be presented in the present work, for more simplicity. We invite the reader to refer to [29] for further information. However, we present here some in formations on the experimental device and the Protocol of the tests.

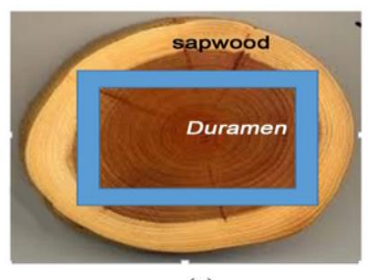

(a)

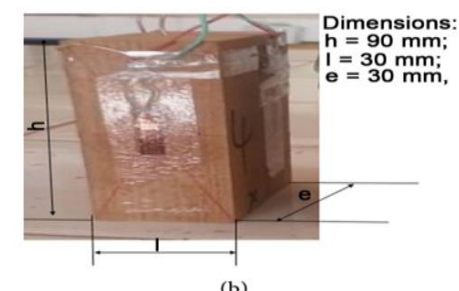

(b)
Figure 2. Zone of extraction of specimen (a) and dimensions of specimen (b)

Wood is a biological, anisotropic, heterogeneous and hygroscopic material. Each species of wood has its own physical properties. In addition, theses physicals and mechanicals properties are all dependent on its moisture content. The knowledge of a mechanical behavior of wood begins with the knowledge of its moisture content and its intrinsic mechanical caracteistics (modulus of elasticity and the failure load ect). The species studied are sapelli and iroko. The $30 \mathrm{~mm} \times 30 \mathrm{~mm} \times 90 \mathrm{~mm}$ compression specimens were taken from the heartwood of each species according to standard NFB 51-003, Figure 2(a) shows the zone of extraction, while Figure 2(b) shows the dimensions of the specimen. The determination of the moisture content was made following the standard NFB 51-004. The moisture content is given by the relation:

$$
H=\frac{m_{H}-m_{0}}{m_{0}} \times 100
$$

where:

- $\quad H$ is the moisture content of the specimen;

- $m_{0}$ is the mass of wood in an anhydrous state;

- $m_{H}$ is the mass of wood with moisture H.

The average humidity rate for our essences obtained during the tests was $19 \%$ for the sapelli and $15.82 \%$ for the iroko.

The determination of maximum stress followed the standard NFB 51-007. The test consisted of monotonic compressive loading at low velocity until failure of the specimen. The average breaking stress of the species determined by standard NFB 51-007 were 47.98 Mpa for sapelli and 45.80 Mpa for iroko for the obtained moisture contents. For the determination of the Damage cyclic compression loading and unloading tests have been made on longitudinal and radial directions of each species. Each cycle consisted of a monotonic loading phase, followed by an elastic unloading. The first load cycle was made at a maximum stress less than one third of the average breaking stress of each species (16Mpa for the sapelli end $15.3 \mathrm{Mpa}$ for the iroko). The value of the maximum stress for each cycle was incremented in the next cycle and the cycles were repeated until the specimen failed. The maximum cycle number was 06 for the longitudinal direction and 05 for the radial direction. The machine used for the tests was a motorized hydraulic compression machine of the DMY brand. The temperature of the experimental environment was stabilized at $23^{\circ} \mathrm{C}$.

\section{RESULTS AND DISCUSSIONS}

The envelope curves of the cyclic compression tests obtained by Fothe et al. [29] were plotted and approximated by the models of Mazar-Pijaudiercabot and Fosao-Foudjet. It is observed that both models give a good approximation of the stress-strain curve for stress levels below the yield stress where 
the material exhibits linear behavior. For the zone with nonlinear behavior, we observe divergences between the approximations of the two models. These divergences depend on the parameters $\lambda_{0}$ and $\lambda_{1}$ chosen for the Fozao-Foudjet 2 model; For certain values of these parameters, 1 and 0 respectively, one obtains a superposition of the Fozao-Foudjet curves on the Mazar-pijaudiercabot curves. This is easily explained by the fact that the Fozao-Foudjet model derives from the Mazars model by the introduction of the parameters $\lambda_{0}$ and $\lambda_{1}$. For other values of these parameters, the divergence between these two models is such that the curves of the FozaoFoudjet model are closer to the experimental curves than that of Mazar-pijaudiercabot; thus making the Fozao-Foudjet model more apt to describe the stress-strain relation than the Mazar-pijaudiercabot model. The following Figures 3 a-d represent the experimental envelope curves and those proposed by the two models for certain values of $\lambda_{0}$ and $\lambda_{1}$ defined such as $1.00 \leq \lambda_{0} \leq 1.38$ and $0.0 \leq \lambda_{1} \leq 0.13$. For specimens in different directions.
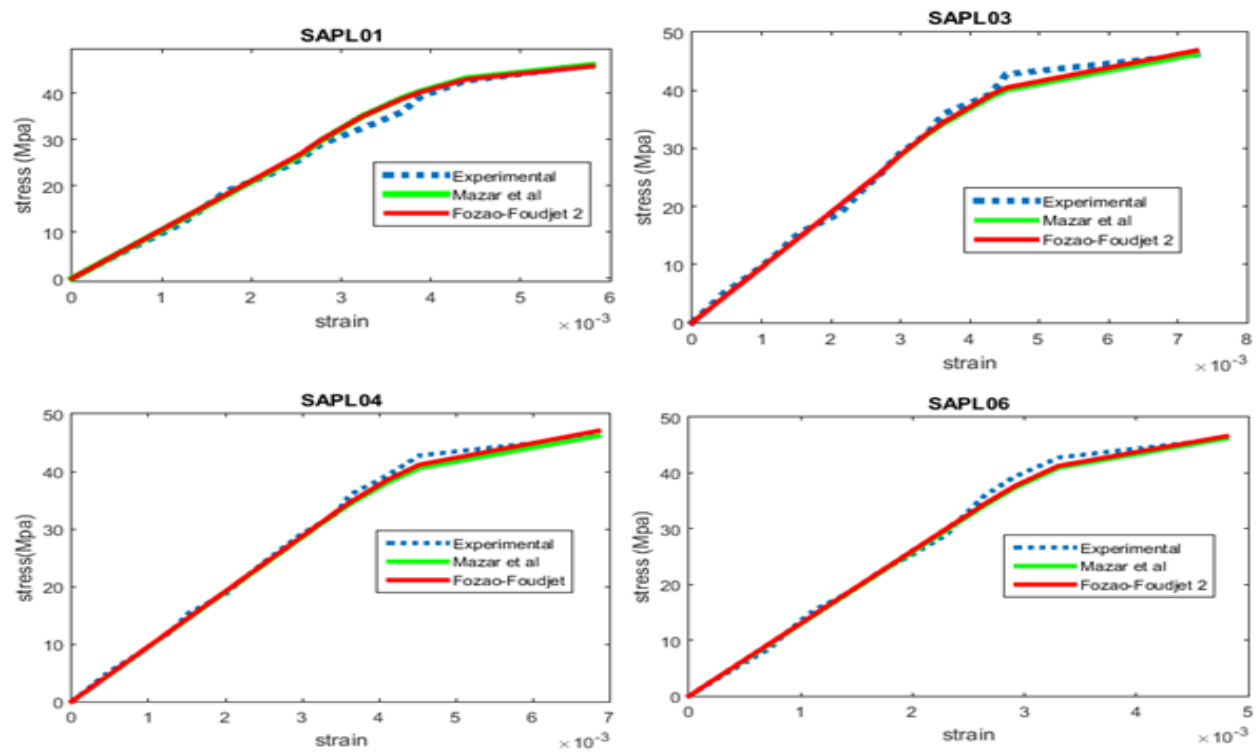

(a) Measured and calculated data compared Sapelli in longitudinal Direction
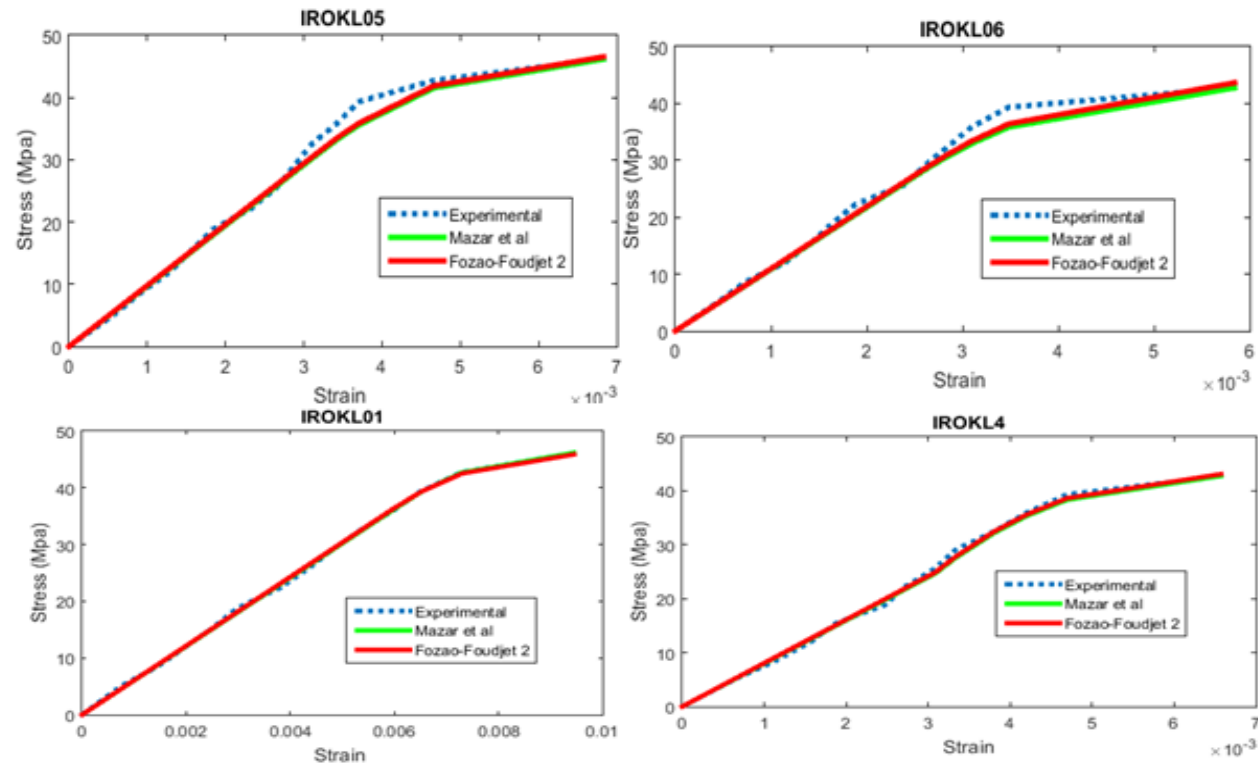

(b) Measured and calculated data compared Iroko in longitudinal Direction
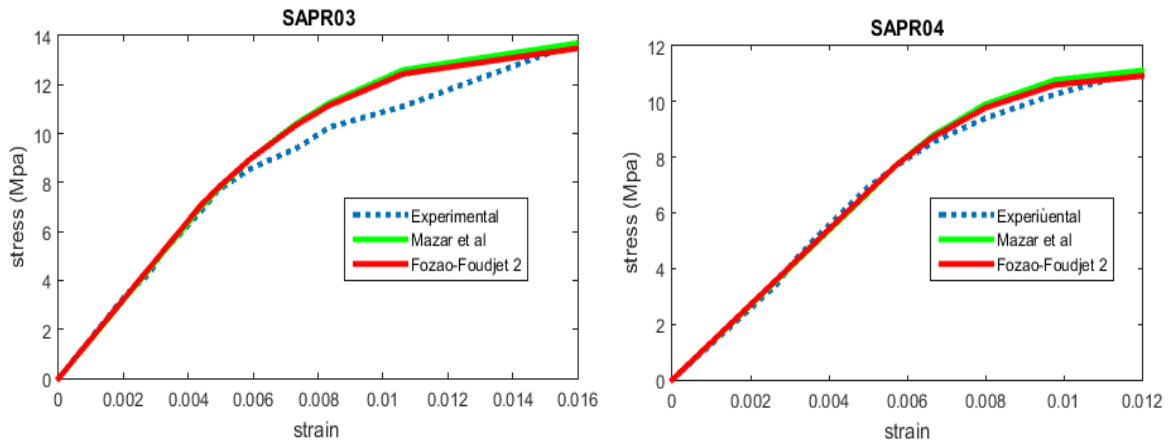

(c) Measured and calculated data compared Sapelli in Radial Direction 

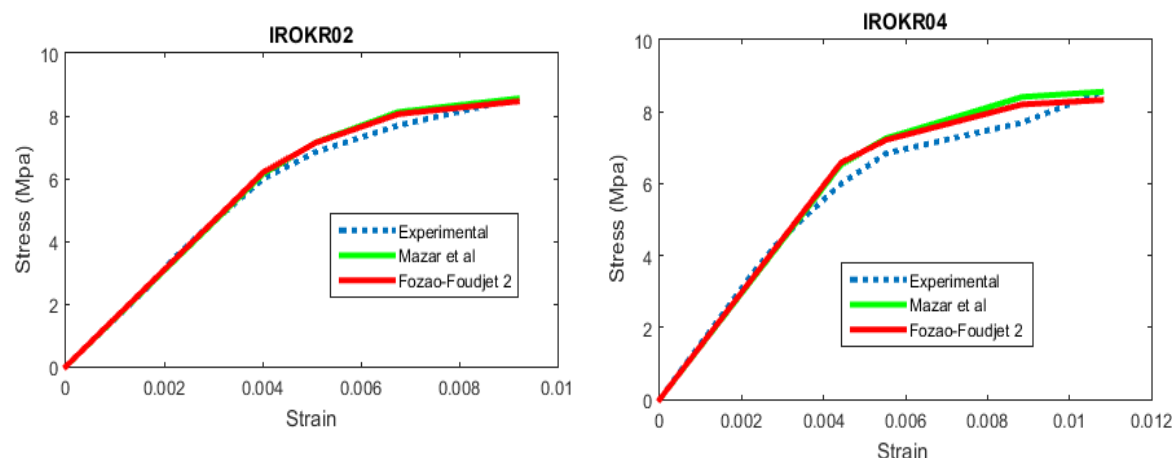

(d) Measured and calculated data compared Iroko in Radial Direction

Figure 3. Measured and calculated data compared

The following Tables 2-5 present the values of the parameters used in the plotting of the curves of the preceding figures. The coefficient of determination $R^{2}$ [8] for the two models was calculated for each sample by the relation:

$$
R^{2}=1-\frac{\sum_{1}^{n}\left(\sigma_{\exp }^{i}-\sigma_{c a l}^{i}\right)}{\sum_{1}^{n}\left(\sigma_{\exp }^{i}-\bar{\sigma}_{\exp }\right)}
$$

where:

- $\sigma_{\exp }^{i}$ is the experimental value of the stress;

- $\sigma_{c a l}^{i}$ is the value of the stress calculated by the model;

- $\bar{\sigma}_{\text {exp }}$ is the mean value of the experimental stress

The results are given in the following Tables 2-5.

It comes from the preceding Tables 2-5 that the values of the parameters and for each of the wood species and in each of the two directions are defined such that: $0.00 \leq \lambda_{0} \leq 0.015$ and $0.99 \leq \lambda_{1} \leq 1.05$. These values are lower than those proposed by Fozao-Foudjet in their study on bamboo. This difference can be explained by the fact that although they are both organic materials, wood and bamboo do not have the same cellular structure. The values of the coefficients of determination for each model and for all the test pieces in longitudinal directions of sapelli and iroko are such that $R^{2} \geq 98.86 \%$. For the radial directions, this coefficient of determination for the great majority of specimens is such that: $R^{2} \geq 95.76 \%$. These observations allow to conclude that the models of MazarPijaudierCabot and Fozao-Foudjet give good descriptions of the stress relation of formation of the wood material subjected to cyclic compressions.

However, for the entire test specimen, the coefficient of determination of the Fozao-Foudjet model is higher than that of theMazar-Pijaudiercabot model. This shows quantitatively that for the parameters and chosen such as $0.00 \leq \lambda_{0} \leq 0.015$ and $0.99 \leq \lambda_{1} \leq 1.05$. The Fozao-Foudjet 2 model gives a better description of the stress-strain relationship than the MazarPijaudiercabot mode.

Table 2. Parameters used in the models for Sapelli in the longitudinal direction

\begin{tabular}{|l|c|c|c|c|c|c|c|c|c|c|c|c|}
\hline \multicolumn{4}{|c|}{} & \multicolumn{4}{c|}{ Mazar's Equation } & \multicolumn{4}{|c|}{ Fozao-Foudjet 2 } \\
\hline specimen & $E_{0}(\mathrm{Mpa})$ & $\sigma_{\text {cmax }}(\mathrm{Mpa})$ & $\begin{array}{c}\varepsilon_{c} \\
\left(\mathrm{x} 10^{-3}\right)\end{array}$ & $\begin{array}{c}\varepsilon_{0} \\
\left(\mathrm{x} 10^{-3}\right)\end{array}$ & $\lambda_{0}$ & $\lambda_{1}$ & $B$ & $\begin{array}{c}\mathrm{R}^{2} \\
(\%)\end{array}$ & $\lambda_{0}$ & $\lambda_{1}$ & $B$ & $\begin{array}{c}\mathrm{R}^{2} \\
(\%)\end{array}$ \\
\hline SAPL01 & 10482.38 & 46.18 & 5.8 & 2.5 & 1.00 & 0.00 & 2.43 & 99.24 & 1.02 & 0.010 & 2.35 & 99.37 \\
\hline SAPL02 & 9392.17 & 46.18 & 7.00 & 2.70 & 1.00 & 0.00 & 2.03 & 99.86 & 1.01 & 0.010 & 1.96 & 99.86 \\
\hline SAPL03 & 9506.12 & 46.18 & 7.3 & 2.73 & 1.00 & 0.00 & 1.83 & 99.46 & 0.99 & 0.0001 & 1.89 & 99.58 \\
\hline SAPL04 & 9506.12 & 46.18 & 6.9 & 3.4 & 1.00 & 0.00 & 1.95 & 99.60 & 0.99 & 0.01 & 2.03 & 99.73 \\
\hline SAPL05 & 13584.54 & 46.18 & 4.9 & 2.1 & 1.00 & 0.00 & 1.90 & 99.71 & 0.99 & 0.010 & 1.90 & 99.74 \\
\hline SAPL06 & 12919.52 & 46.18 & 4.8 & 2.6 & 1.00 & 0.00 & 2.21 & 99.49 & 0.99 & 0.015 & 2.21 & 99.61 \\
\hline
\end{tabular}

Table 3. Parameters used in the models for Iroko in the longitudinal direction

\begin{tabular}{|c|c|c|c|c|c|c|c|c|c|c|c|c|}
\hline \multirow[b]{2}{*}{ specimen } & \multirow[b]{2}{*}{$E_{0}$} & \multirow[b]{2}{*}{$\begin{array}{l}\sigma_{c \max } \\
(\mathrm{Mpa})\end{array}$} & \multirow[b]{2}{*}{$\begin{array}{c}\mathcal{E}_{c} \\
\left(\mathrm{x} 10^{-3}\right)\end{array}$} & \multirow[b]{2}{*}{$\begin{array}{c}\mathcal{E}_{0} \\
\left(\mathrm{x} 10^{-3}\right)\end{array}$} & \multicolumn{4}{|c|}{ Mazar's Equation } & \multicolumn{4}{|c|}{ Fozao-Foudjet 2} \\
\hline & & & & & $\lambda_{0}$ & $\lambda_{1}$ & $B$ & $\begin{array}{l}\mathrm{R}^{2} \\
(\%)\end{array}$ & $\lambda_{0}$ & $\lambda_{1}$ & $B$ & $\begin{array}{l}\mathrm{R}^{2} \\
(\%)\end{array}$ \\
\hline IROKL01 & 6042.88 & 46.18 & 9.5 & 6.00 & 1.00 & 0.00 & 2.96 & 99.94 & 1.01 & 0.01 & 2.78 & 99.94 \\
\hline IROKL02 & 8068.25 & 42.76 & 6.4 & 4.4 & 1.00 & 0.00 & 3.17 & 99.79 & 1.00 & 0.01 & 3.17 & 99.77 \\
\hline IROKL03 & 9784.42 & 42.76 & 5.2 & 3.7 & 1.00 & 0.00 & 3.47 & 99.68 & 1.00 & 0.01 & 3.47 & 99.71 \\
\hline IROKL04 & 8002.97 & 42.76 & 6.6 & 3.1 & 1.00 & 0.00 & 2.89 & 99.69 & 1.00 & 0.01 & 2.89 & 99.75 \\
\hline IROKL05 & 9725.26 & 46.18 & 6.8 & 3.1 & 1.00 & 0.00 & 1.92 & 98.88 & 1.00 & 0.01 & 1.92 & 99.06 \\
\hline IROKL06 & 10862.97 & 42.76 & 5.8 & 2.6 & 1.00 & 0.00 & 1.76 & 98.86 & 0.99 & 0.01 & 1.83 & 98.99 \\
\hline
\end{tabular}


Table 4. Parameters used in the models for Sapelli in the radial direction

\begin{tabular}{|l|c|c|c|c|c|c|c|c|c|c|c|c|}
\hline \multicolumn{19}{|c|}{} & \multicolumn{4}{c|}{ Mazar's Equation } & \multicolumn{4}{|c|}{ Fozao-Foudjet 2 } \\
\hline specimen & $E_{0}(\mathrm{Mpa})$ & $\sigma_{c \max }(\mathrm{Mpa})$ & $\begin{array}{c}\varepsilon_{c} \\
\left(\mathrm{x} 10^{-3}\right)\end{array}$ & $\begin{array}{c}\varepsilon_{0} \\
\left(\mathrm{x} 10^{-3}\right)\end{array}$ & $\lambda_{0}$ & $\lambda_{1}$ & $B$ & $\begin{array}{c}\mathrm{R}^{2} \\
(\%)\end{array}$ & $\lambda_{0}$ & $\lambda_{1}$ & $B$ & $\begin{array}{c}\mathrm{R}^{2} \\
(\%)\end{array}$ \\
\hline SAPR01 & 1424.60 & 13.68 & 15.9 & 4.8 & 1.00 & 0.00 & 1.53 & 94.99 & 1.02 & 0.01 & 1.44 & 95.76 \\
\hline SAPR02 & 1485.28 & 13.68 & 10.00 & 4.5 & 1.00 & 0.00 & 3.73 & 90.72 & 0.99 & 0.01 & 3.78 & 91.77 \\
\hline SAPR03 & 1592.15 & 13.68 & 15.87 & 4.4 & 1.00 & 0.00 & 1.26 & 97.10 & 1.02 & 0.01 & 1.26 & 97.51 \\
\hline SAPR04 & 1339.33 & 11.11 & 12.00 & 4.9 & 1.00 & 0.00 & 1.95 & 99.31 & 1.02 & 0.01 & 1.82 & 99.59 \\
\hline SAPR05 & 1321.76 & 11.11 & 11.3 & 5.3 & 1.00 & 0.00 & 2.32 & 97.21 & 1.02 & 0.01 & 2.15 & 97.80 \\
\hline
\end{tabular}

Table 5. Parameters used in the models for Iroko in the radial direction

\begin{tabular}{|c|c|c|c|c|c|c|c|c|c|c|c|c|}
\hline \multirow[b]{2}{*}{ specimen } & \multirow[b]{2}{*}{$E_{0}(\mathrm{Mpa})$} & \multirow[b]{2}{*}{$\sigma_{c \max }(\mathrm{Mpa})$} & \multirow[b]{2}{*}{$\varepsilon_{c}\left(\mathrm{x} 10^{-3}\right)$} & \multirow[b]{2}{*}{$\begin{array}{c}\varepsilon_{0} \\
\left(\times 10^{-3}\right)\end{array}$} & \multicolumn{4}{|c|}{ Mazars Equation } & \multicolumn{4}{|c|}{ Fozao-Foudjet 2} \\
\hline & & & & & $\lambda_{0}$ & $\lambda_{1}$ & $B$ & $\begin{array}{l}\mathrm{R}^{2} \\
(\%)\end{array}$ & $\lambda_{0}$ & $\lambda_{1}$ & $B$ & $\begin{array}{l}\mathrm{R}^{2} \\
(\%)\end{array}$ \\
\hline IROK R01 & 1227.35 & 8.55 & 13.6 & 4.9 & 1.00 & 0.00 & 0.91 & 99.28 & 1.01 & 0.00 & 0.86 & 99.29 \\
\hline IROK R02 & 1531.48 & 8.55 & 9.20 & 4.00 & 1.00 & 0.00 & 1.29 & 99.46 & 1.02 & 0.01 & 1.20 & 99.51 \\
\hline IROK R03 & 739.67 & 8.55 & 19.2 & 8.4 & 1.00 & 0.00 & 1.24 & 99.38 & 1.02 & 0.01 & 1.16 & 99.36 \\
\hline IROK R04 & 1474.80 & 8.55 & 10.8 & 4.4 & 1.00 & 0.00 & 0.88 & 98.19 & 1.05 & 0.01 & 0.75 & 98.49 \\
\hline IROK R05 & 1058.14 & 8.55 & 16.4 & 5.8 & 1.00 & 0.00 & 0.81 & 99.69 & 1.00 & 0.00 & 0.76 & 99.73 \\
\hline
\end{tabular}

\section{CONCLUSIONS}

This work investigated the relative capacities of two damage models to describe the stress-strain relationship of wood materials subjected to cyclic compressive stresses. The models object of this study are the models of Mazar-Pijaudier Cabot and the model of Fozao-Foudjet 2. The experimental envelopes curves obtained from cyclic compression tests on the longitudinal and radial directions of the sapelli and the iroko were drawn and compared to the envelope curves proposed by each of the two models. The calculation of the coefficient of determination $\mathrm{R}^{2}$ for each of the models was also carried out.

The results show a good agreement between the experimental curves and the two mathematical models. For the Fozao-Foudjet 2 models, this good agreement is obtained from the parameters $\lambda_{0}$ and $\lambda_{1}$ chosen as $0.00 \leq \lambda_{0} \leq 0.015$ and $0.99 \leq \lambda_{1} \leq 1.05$. The parameters of the model of Fozao-Foudjet 2 , retained for the modeling of the cyclic compression of wood are thus defined such as $0.00 \leq \lambda_{0} \leq 0.015$ and $0.99 \leq \lambda_{1} \leq 1.05$.

Moreover, for the parameters and chosen such as $0.00 \leq \lambda_{0} \leq 0.015$ and $0.99 \leq \lambda_{1} \leq 1.05$. The coefficient of determination for the Fozao-Foudjet 2 model is greater than that of the Mazar-Pijaudiercabot model for all of the two directions. This makes the Fozao-Foudjet 2 model a better candidate for describing the behavior of wood material subjected to cyclic compressions.

\section{REFERENCES}

[1] Guitar, D. (1987). Mécanique du Matériau Bois et Composite, Collection nabla.

[2] Kollmann, F.F.P., Cote, W.A. (1968). Principles of Wood Science and Technology. Volume 1, Solid Wood. Springer-Verlag, New York.

[3] Van Der Put. (1989). Deformation and Damage Processes in Wood. Delft University Press. http://resolver.tudelft.nl/uuid:ac2ea262-be4d-48c2-

\section{9f10-f35bd7c14a05}

[4] Thibaut, B., Gril, J., Fournier, M. (2001). Mechanics of wood and trees: Some new highlights for an old story. C. R. Acad. Sci. Paris, t. 329, Série II $b$, 701-716.

[5] Aira, J.R., Íñiguez-González, G. (2014). Determination of the elastic constants of scots pine (pinus sylvestris 1.) wood by means of compression tests. Biosysteme Engineering, 1261: 2-22. https://doi.org/10.1016/j.biosystemseng.2014.07.008

[6] Nziengui, C.F.P., Ikogou, S., Pitti, R.M. (2017). Impact of cyclic compressive loading and moisture content on the mechanical behavior of Aucoumea Klaineana Pierre. Wood Material Science \& Engineering, 13(4): 190-196. https://doi.org/10.1080/17480272.2017.1307281

[7] Edzang, A.C.E., Nziengui, C.F.P., Ango, S.E., Ikogou, S. Pitti, R.M. (2020). Comparative studies of three tropical wood species under compressive cyclic loading and moisture content changes, Wood Material Science \& Engineering.

https://doi.org/10.1080/17480272.2020.1712739

[8] Houanou, A.K., Tchéhouali, A.D., Foudjet, A.E. (2014). Effect of the loading duration on the linear viscoelastic parameters of tropical wood: Case of Tectona grandis L.f (Teak) and Diospyros mespiliformis (Ebony) of Benin Republic. $\quad$ Springer Plus 3: 74. https://doi.org/10.1186/2193-1801-3-74

[9] Foadieng, E., Fogue, M., Talla, P.K., Ntabe, E. (2017). Effets de la Variation du Taux d'Humidité sur les Propriétés Mécaniques de Mélicia exelcia (iroko) $6^{\text {ieme }}$ journées du grd 3544 « sciences du bois » Nantes pp 5657. https://hal-enpc.archives-ouvertes.fr/hal-01713401

[10] Azeufack, U.G., Kenmeugne, B., Foadieng, E. Fouotsa, M., Talla, P.K., Fogue, M. (2019). Mechanical characterization and measurement of damage of Pericopsis Elata (Assamela). World Journal of Engineering and Technology, 7(2): 256-269. https://doi.org/10.4236/wjet.2019.72017

[11] Lemaitre, J. (1996). A Course on Damage Mechanics. Springer-Verlag. https://doi.org/10.1007/978-3-642- 
$18255-6$

[12] Lemaitre, J., Desmorat, R. (2005). Engineering Damage Mechanics. Springer. https://doi.org/10.1007/b138882

[13] Lemaitre, J., Chaboche J.L., Benalal, A., Desmorat, R. (2009). Mécanique des Matériaux Solides, Dunod.

[14] Murakami, S. (2012). Continium Damage Mechanics. Springer-Verlag. https://doi.org/10.1007/978-94-0072666-6

[15] Kachanov, L.M. (1958). Time of rupture process under creep conditions. Otdelenie Tekhniecheskichnauk, 8: 2631. https://ci.nii.ac.jp/naid/10030415483/en/.

[16] Lemaitre, J., Dufailly, J. (1987). Damage measurements. Engineering Fracture Mechanics, 28(5-6): 643-647. https://doi.org/10.1016/0013-7944(87)90059-2Get

[17] Meng, Q., Wang, Z. (2016). Creep damage models and applications for crack growth analysis in pipes: A review. Engineering Fracture Mechanics. http://dx.doi.org/10.1016/j.engfracmech.2015.09.055

[18] Wang, M.Q., Song, X.B., Gu, X.L. (2018). Threedimensional combined elasto-plastic and damage model for nonlinear analysis of wood. American Society of Civil Engineers, 144(8). https://doi.org/10.1061/(ASCE)ST.1943-541X.0002098

[19] Sandhaas, C. (2011). 3D material model for wood, based on continuum damage mechanics. Stevinrapport 6-11-4, Stevin II Laboratory. Delft University of Technology, The Netherlands.

[20] Khelifa, M., Khennane, A., El Ganaoui, M., Celzard, A. (2016). Numerical damage prediction in dowel connections of wooden structures. Mater Struct., 49: 1829-1840. https://doi.org/10.1617/s11527-015-0615-5

[21] Khennane, A., Khelifa, M., Bleron, L., Viguier, J. (2014). Numerical modelling of ductile damage evolution in tensile and bending tests of timber structures. Mech Mater. 68:

228-236. https://doi.org/10.1016/j.mechmat.2013.09.004

[22] Mazars, J., Pijaudier-Cabot, G. (1989). Continuum damage theory. Application to concrete. J Engng Mech ASCE, $115(2)$ : 345-365. https://doi.org/10.1061/(ASCE)0733-
9399(1989)115:2(345)

[23] Sima, J.F., Roca, P., Molins, C. (2007). Cyclic constitutive model for concrete. Engineering Structures, 30(3) 695-706. https://doi.org/10.1016/j.engstruct.2007.05.005

[24] Faria, R., Oliver, J., Cervera, M. (1998). A strain-based plastic viscous-damage model for massive concrete structures. Int J Solids Struct., 35(14): 1533-58. https://doi.org/10.1016/S0020-7683(97)00119-4

[25] Breccolotti, M., Bonfigli, M.F., D’Alessandro, A., Materazzi, A.L. (2015). Constitutive modeling of plain concrete subjected to cyclic uniaxial compressive loading. Construction and Building Materials, 94: 172180. https://doi.org/10.1016/j.conbuildmat.2015.06.067

[26] Fozao, D.S., Foudjet, A.E. (2020). Stress-strain behaviour of bamboo beyond its elastic limit under uniaxial compressive load, using the principles of plasticity and damage mechanics. Revue Scientifque et Technique Forêt et Environnement du Bassin du Congo, 14: 12-20. http://doi.org/10.5281/zenodo.3737878

[27] Babu, Y.S., Reddy, V.S., Raju, S.P.V., Rao, M.V.S. (2020). A review of mathematical models for prediction of Stress-strain and moment -curvature behaviour in concrete. E3S Web of Conferences, 184: 01111. https://doi.org/10.1051/e3sconf/202018401111

[28] Kaklis, K., Agioutantis, Z., Mavrigiannakis, S., Maravelaki-Kalaitzaki, P. (2019). A simplified damage evolution relationship and deformation characteristics of a pozzolanic lime mortar when subjected to unloadingreloading cycles in the pre-peak region. Frattura ed Integrità $\quad$ Strutturale, $\quad 50: \quad 395-406$. https://doi.org/10.3221/IGF-ESIS.50.33

[29] Fothe, T., Azeufack, U.G., Kenmeugne, B., Talla, P.K., Fogue, M. (2019). Damage evaluation of two equatorial hardwoods under uniaxial compression: Case of Entandrophragma cylindricum (Sapelli) and Chlorophora exelcia (Iroko). World Journal of Engineering and Technology, 7: 549-558. https://doi.org/10.4236/wjet.2019.74039 